\title{
The Effectiveness of Dictation Method in College English Vocabulary Teaching
}

\author{
Qu Tang \\ College of Foreign Studies of Guilin University of Technology, China \\ Email: tangqu1@163.com
}

\begin{abstract}
As known to all, dictation method is an effective way to review and test one's vocabulary. This paper introduces the theories that support dictation method and the effective strategies for applying it. Besides, this paper also explains how the teachers should do to help the students enhance enthusiasm and confidence for learning, stimulate learning motivation, reduce or eliminate their difficulty and take measures to improve their own language skills, so as to raise the efficiency of memorizing vocabulary and achieve the purpose of increasing vocabulary.
\end{abstract}

Index Terms - effectiveness, dictation method, vocabulary teaching

\section{INTRODUCTION}

Vocabulary is a very important but difficult part of language, but the straits of English vocabulary study widely exists. So researches on vocabulary learning have attracted the author's attention. Vocabulary is of primary concern in any second language system and ways of vocabulary study are various, but achieving good learning effect is not easy. So the research to this field shows significant meanings.

Currently, there are some thesis and books about how to improve vocabulary study. And some suggestions have already made to tackle this problem. However, it is hard to find suitable methods for non-English majors in books. So as a college English teacher, the writer of this paper expects to give some advice according to the feature of non-English majors through the investigation and analysis.

\section{THE IMPORTANCE OF VOCABULARY STUDY}

With the tendency of globalization and the frequent exchanges of culture and politics among countries, English, as a worldwide accepted language, becomes more and more important. The fact that more foreigners are coming into and more Chinese are going abroad to study, to a large extent, enhances people's enthusiasm and eagerness to improve their English language abilities.

As we know vocabulary is of primary concern in any second language setting, so as the English. English study involves the study of speech sounds, grammar and vocabulary. Vocabulary has proved particularly important and certainly the most important. Engels once said that vocabulary was basement of language. Linguist Stalin also pointed out that vocabulary is the building material of language and the basis of many communication abilities, such as reading, listening, writing and spoken language. One individual can only express little meaning with grammar. However, nothing can be expressed without vocabulary. Teaching Requirements of College English states that the teaching purpose of college English is to develop students' comprehensive ability to use English, especially their listening and speaking abilities, so as to enable them to effectively carry out oral or written communications in their future work and social interaction, and meanwhile enhance their ability of independent learning and students' comprehensive cultural accomplishment. Therefore, this purpose will never be realized unless the students can memorize certain vocabulary. According to the new requirements, students should master 5,500 words and 1200 phrases, which indicate that vocabulary teaching has been the key to learn English. However, most non-English major students in our university, Guilin University of Technology, (especially the students majoring in engineering) have not laid a solid basis for English learning and the biggest obstacle for them is the poor vocabulary, which has encumbered the improvement of interpersonal skills and their listening, speaking, reading and writing abilities. In other words, it has been a bottleneck for the students' English learning. With respect to words memory, although they have spent lots of time on it, little success has been made. What's worse, few students have found an effective way to memorize English words. Therefore, how to help the students memorize the English words, the most boring but also the most basic and important things in English learning, and enrich their vocabulary in a short time has been a difficult problem in college English teaching.

There are several common problems in present English vocabulary teaching, such as (1) the students are unable to understand so many grammar knowledge and use them in English listening, speaking, reading and writing; (2) the repetition frequencies of the same words are so low that students can not memorize the words they have learned; (3) vocabulary teaching does not distinguish common words from uncommon words, which makes students bear more burden to memorize the vocabulary; (4) present vocabulary teaching lacks logics and does not reveal the regularity of 
English words. Therefore, with the aim of solving the problems in vocabulary teaching and helping the students find an effective way to enrich their vocabulary, Guilin University of Technology establishes a task group, called Empirical Research on the College English Vocabulary Teaching, so as to apply many strategies, such as word formation, application of vocabulary, words explanation and interesting explanation, to English teaching, and make a comparison experiment about vocabulary teaching. And the writer of this paper is responsible for one part of this comparison experiment, i.e. the role of dictation method in vocabulary teaching. It has to be admitted that traditional vocabulary teaching can benefit students' vocabulary learning, but it also has its limitations and shortcomings, especially its ignorance about vocabulary test. However, as a means to test vocabulary, dictation method is demonstrated to be effective. And a comparison experiment about dictation method was made between two classes, grade 2008, majoring in gemology and telecom respectively since March, 2009, so as to enrich students' vocabulary through the dictation method.

\section{Methodology}

\section{A. Subjects of the Experiment}

This experiment chooses two classes of sophomore of Guilin University of Technology as experiment subjects, including 40 students of Class one, Grade 2008, majoring in gemology (treatment class)and 45 students of Class 2 , Grade 2008, majoring in telecom(comparison class).

\section{B. Textbook of the Experiment}

All the experiment subjects use the same textbook, that is, book III and book IV of New College English.

\section{Experimental Method}

The treatment class makes use of dictation method to help students memorize vocabulary, mainly through increasing the times of dictation (for example, dictation is done in every English lesson) and constantly changing the mode of dictation (for example, compound dictation and words connection); however, the comparison class employs the original mode of dictation that words are dictated for one time per unit, and the students write down the words according to the teacher's pronunciation and give their corresponding Chinese meaning.

\section{Design of Test}

In order to evaluate the students' progress, this experiment plans two tests which use the same test paper. The test paper contains 100 CET 4 words and requires the students to choose the right meanings from the options for the given words (one point per word). The students should finish the test paper in 15 minutes. And the experiment will take the average score as data analysis. In addition, the first test should be done one week before the beginning of the experiment so as to define the overall difference between these two classes. Two months after the end of the experiment, the students take the second test, with the aim of determining the effect of this mode.

E. Comparison of Vocabulary Scores before and after the Experiment of Dictation Method

\begin{tabular}{|l|l|l|}
\hline \multirow{2}{*}{ Class } & Average Scores \\
\cline { 2 - 3 } & Before the experiment & After the experiment \\
\hline Treatment class & 59.3 & 75 \\
\hline Comparison class & 62.9 & 64 \\
\hline
\end{tabular}

The data of the table above reveals that the students of two classes do not do a good job in vocabulary and are at the similar level. Although the students of both classes have improved their vocabulary scores, the score of the treatment class is significantly higher than that of the comparison class. This result demonstrates that the students of the treatment class have significantly enlarged their vocabulary.

\section{THEORETICAL BASIS FOR DictATION METHOD}

After 1960s, research into vocabulary learning strategies began to arouse the linguistics' interest in western countries. In recent years, considerable researches have been done in the area of language study, but vocabulary-learning strategies have attracted relatively less attention. However, it does not follow that no achievement has been obtained. Following are some strategies that applied into vocabulary learning.

\section{A. Social Strategies}

Social strategies involves students enlisting teachers to check their work for accuracy, especially flash cards and word lists, since these are commonly used for independent learning outside class.

\section{B. Memory Strategies}

Most memory strategies involve relating the word to be retained with some previously learned knowledge, using some form of imagery, or grouping. 


\section{Picture/Imagery Strategies}

New words can be learned by studying them with pictures of their meaning instead of definition. Imagery has been shown to be more effective than mere repetition for reading passages and sentences, suggesting it should well be more effective for vocabulary, too.

\section{Related Words and Unrelated Words}

Likewise, new words can be linked to L2 words, which the students already know. Usually this involves some type of sense relationship, such as coordination synonymy, or antonym. Words association research has shown that coordinates in particular have very strong connective bonds these and other sense relationships can be illustrated with semantic maps, which are often used to help consolidate vocabulary.

The learner can also link words together that have no sense relationships. One first memorizes a rhyme like "one is a bun, two is a shoe, three is a tree." Then an image is created of the word to be remembered.

\section{E. Grouping}

Grouping is an important way to aid recall, and people seem to organize words into groups naturally without prompting. Grouping words can be done in the way of writing the synonyms or related words together, or words can be grouped together in a very natural way by using the target words in sentences. Similarly, words can be grouped together in a story. The narrative chain method has been shown to be more effective.

From above description we know that many strategies can be used to help students enlarge their vocabulary, however, dictation method, as one of the most common and traditional ways for remembering words, is rare to be mentioned. It is an unforgettable way that is worth making a research on it.

Vocabulary means the total number of words that make up a language and accordingly, vocabulary learning strategies in earlier researches refer to those techniques that help to commit those words into memory.

The brain of human is a treasure of memory. Memory is usually defined as retaining cognitive things in the brain for a long time, which is the key to learn and master English vocabulary. According to the forgetting curve proposed by the famous German psychologist Ebbinghaus, memory can be classified into short-term memory and long-term memory. Input information becomes human beings short memory through the process of study. If human do not review the input information in time, they will easily forget these information. However, timely review can develop short-term memory into long-term memory which will retain in brain for a long time. In other words, forgetting is a regular but also unbalanced thing. At the initial stage of memory, human beings forget input information very quickly, and then the pace gradually slows down. After a certain period of time, almost nothing could be forgotten. If the students do not review what they have learned in time, they can only master $25 \%$ of the knowledge. Therefore, according to the forgetting curve, teachers should give timely dictation to the students so as to develop short-term memory into long-term memory. And finally, students' vocabulary will be enlarged gradually through dictation method.

\section{StRategies For Dictation Method}

Dictation should have a focus and employ appropriate strategies.

(1). Teachers should take the words that can not explained and spelled through pronunciation, formation rules and stereotype mode, such as the words with double consonants and homophone affixes, as well as some confusing words. Of course, these representative words that can reveal English pronunciation and formation rules should not be ignored.

(2). Teachers should lay emphasis on the dictation frequencies of CET 4 and 6 vocabularies so as to make the students familiar with the spelling of the vocabulary. For example, teachers should dictate the bold words, especially the bold words with a $\boldsymbol{\Lambda}$ sign (book III and book IV of New College English) for several times.

(3). From the perspective of memory psychology, too many words per time are not beneficial for memory. Therefore, 20-30 words are appropriate per time.

(4). Independent revision to the dictation. College English Teaching Requirements encourage independent learning and require the students to finish learning task independently under the guidance of teachers. Therefore, the teacher should formulate strict requirements and the students must correct their spelling mistakes independently.

(5). Dictation scores should be counted as a part of daily scores.

\section{POINTS FOR ATTENTION}

Dictation is mainly aimed at checking students' pronunciation and their knowledge of spelling rules and corresponding Chinese meanings. During the process of dictation, students make use of input skills and output skills and write down the words through their hands, pens and ears, so as to check the effect of dictation and enhance their understanding and memory of English words. According to the experiment results, a conclusion is reached that dictation is an effective quantization strategy, which can reveal students' vocabulary and learning outcomes to some extent. However, teachers should pay much attention to the following points.

\section{A. Urging the Students to Improve English Pronunciation and Intonation}

Dictation is the combining of listening and writing. Therefore, the traditional pattern of dictation that students write 
down the words according to teachers' pronunciation should be improved. The students of the university are from the four corners of China, especially from Guangxi Zhuang Autonomous Region. Due to the influence of their mother tongue or dialects, there are different levels of gap between their pronunciation and standard pronunciation. For example, they can not distinguish /1/ from /n/, and /c/ from /z/. During the process of dictation, the phonological representations of the mental lexicon are first activated. Then the semantic representations are activated by phonological representations. Therefore, correct pronunciations of vocabulary are crucial to dictation. Otherwise, the students will not be able to write down the words corresponding to the pronunciation, not to mention effective activation of words' semantic representations. Accordingly, the teachers should try their best to standardize their own pronunciation when teaching new words. Besides, the students must practice pronunciation repeatedly so as to correct their own pronunciation mistakes and standardize their pronunciation. All in all, only correct input can lead to correct output.

\section{B. Having a Correct Attitude towards Vocabulary Learning}

Word dictation requires students to pay attention to the form, pronunciation and meaning of English words. However, it usually leads to a bad habit of superficial memory and at last makes the students lose their enthusiasm for vocabulary learning. Besides, there is also a common phenomenon that some students can not make sentences although they can write down almost all the words. In fact, this phenomenon can be explained by the properties of mental lexicon, i.e. the different levels of mental lexicon is not isolated but mutually associated. Therefore, the teachers should try their best to improve students' ability of using words and expand the depth and breadth of their mental lexicon. For example, while giving them dictation, the writer of this paper requires the students to make sentences.

\section{Employing a Diversified Dictation Strategy so as to Overcome the Emotional Barriers and Anxiety}

Before conducting this experiment, a questionnaire investigation is carried out between treatment class and comparison class, and there are altogether 13 items in the questionnaire which include students' attitude towards words dictation, the amount of the words, the period of one dictation, independent correction or not and the effect of dictation etc. The purpose of the questionnaire is to find the students' attitude towards dictation and the frequency of the dictation that teaches use to test the students' vocabulary. Following is the overall description of the questionnaire.

Item 1: $80 \%$ of the students select B (teachers often dictate English words), 20\% select C (sometimes, teachers dictate English words). In general, dictation method is a means used by teachers to check the students' vocabulary.

Item2: $90 \%$ of the students select A and $10 \%$ select B, which demonstrates that teachers still focus on students' memory of new words.

Item 3: $100 \%$ of the students select A, which demonstrates that the students hope the teachers to help them memorize the new words.

Item4 $85 \%$ of the students select $\mathrm{B}$, which shows that the teacher usually dictate words one time per unit.

Item5 50\% of the students select A and the rest students select B, in other words, one half of the students prefer one time per unit and another half prefer two times per unit. But they all reveal a fact that all of them are willing to increase the frequency of dictation.

Item $675 \%$ of the students select $\mathrm{C}$ and $25 \%$ select $\mathrm{B}$, that is, the teacher often dictate 11-30 words one time.

Item $780 \%$ of the students select $\mathrm{C}$, which demonstrate that students are able to memorize 30 words in a short time.

Item8 $40 \%$ of the students select B, $20 \%$ select C and the rest select D. Even few students select E, which demonstrates that the students lack the awareness of independent learning. They only focus on the process of dictation but ignore its result.

Item $990 \%$ of the students select $\mathrm{B}$, which demonstrates students also think that dictation is an important means to check their vocabulary.

Item $10100 \%$ of the students select B, which demonstrates that dictation can prompt the students to remember the new words in time.

Item11 Students' selections are too scattered, which is caused by all kinds of reasons, for example, forcing themselves to memorize words and hating memorizing words.

Item $12100 \%$ of the students select B, which demonstrates that students think that dictation is useful.

Item $1390 \%$ of the students select B, which indicated that students would like to have dictation in this semester.

According to the statistics of this questionnaire investigation, the writer finds that most students consider dictation method as an ideal means to check their vocabulary. But the real effect is not so significant and repeated dictation usually leads to students' boredom and less enthusiasm. Moreover, during the process of dictation, students' poor vocabulary can also result in some psychological barriers, such as anxiety, tension, depression, fear and so on. Therefore, the teachers should help the students enhance their enthusiasm and confidence for learning, reduce or eliminate their psychological barriers and take measures to improve their language skills. All in all, the teachers should pay attention to the following points:

(1) The teachers should make use of different dictation methods and pay attention to the diversity of its content, methods and forms. For example, in terms of methods, the teachers can ask the students of three levels (A, B, C) to write down the words on blackboard and the rest on their own desks, and then ask the students to correct spelling mistakes by themselves. Moreover, the teachers can also give some prefixes and suffixes and then require the students to write down some words associated with the prefixes and suffixes. For instance, the teacher can ask the students to 
give five words with the suffix -able, such as cable, fable, table, disable, enable, liable etc.; in terms of content, the teachers can ask them to write down some words, sentences, and even paragraphs; and in terms of correction, a combination of mutual correction between students and teacher's correction is a better method.

(2) The teacher should show respect to individual differences. The College English Teaching Requirements formulated by the Ministry of Education requires the teachers to lay emphasis on the majority but also show respect to individual differences. It is inevitable that students have different levels of basic knowledge and comprehensive capacity of using language, therefore, the teacher should not use only one pattern of dictation for all students. Instead, the teacher should not only ask the top students to be strict with themselves, but also help the students with poor performance to establish confidence. The teacher can also encourage the students sometimes, so as to activate their enthusiasm for learning. and the writer of this paper gives dictation in a special way that the students mark their own dictation and classify the 40 students of treatment class into A(6 students), B(15 students), C(13students) and D (6 students)groups. Then, the writer sets passing scores for A, B and C groups, for example, 80, 70 and 60 points respectively. As for group $\mathrm{D}$, they can set passing scores (in the range of 10-60 points) by themselves according to their own abilities. And during the following dictations, the teacher should record their real scores, encourage the top students to win full mark and stimulate the students with poor performance to make progress.

\section{Supplementing the Dictated Words with Their Context and Word Formation}

There is an incomplete mapping between words and their meanings, not to mention a cross-language corresponding relationship between words and meanings. Therefore, the traditional pattern of dictation that requires students to give Chinese meanings to each word lacks rational and scientific evidence. In fact, the meaning of one word varies due to its context. So the teachers can supplement the words with their context, for example the sentences of the texts, so as to let the students understand that the meaning of one word depends on its context and urge the students to review the sentences and content of the texts. English is one of the languages with the largest vocabulary, but there is a law that governs its word formation. From the perspective of word construction, it can be found that there is direct or indirect relationship between English words. Therefore, the teachers can help the students to make use of the law to memorize English words. For example, the Chinese meaning of the affix lun is "moon", if some suffixes are added to it, many new words will be coined, such as lunar (of moon), uniform (moon-like), lunate (new moon-like), demilune (half moon), plenilune (full moon) and so on.

\section{CONCLUSION}

Memorizing words is one of the keys to learn English and also the most boring task for many Chinese students. The writer of this paper applies dictation method into vocabulary teaching so as to help the students to effectively memorize English words. And great achievements have been made through our efforts. Meanwhile, the writer realizes that dictation should not be isolated. Instead, the teacher should make use of more methods to increase students' enthusiasm and improve their efficiency of memorizing words. And only in this way can the students properly use English vocabulary and improve their comprehensive capacity.

Of course, the expanding of vocabulary, on one hand, is a process of increasing the amount of words; on the other hand, it is a meaningful store tightly connected with the languages invents in modern science, technology, social and economic to express new things and new changes. So to an English learner, the expanding of English vocabulary is endless.

\section{REFERENCES}

[1] Carter R ,B, McCarthy. (1988). Vocabulary and Language Teaching. London: Longman Press.

[2] Gui Shichun. (1996). New Psycholinguistics. Shanghai: Shanghai Foreign Language Teaching Press.

[3] Guo Chengfang. (2006). A investigation on college students' vocabulary and capacity of using vocabulary. Journal of Anhui Agricultural University (Edition of Social Science), 1, 56-59.

[4] Han Ge. (2005). How to teach vocabulary. Journal of Beijing International Studies University, 2, 34-36.

[5] Jiao Yan. (2006). How to memorize college English vocabulary: From the perspective of Ebbinghaus' Forgetting Curve. Journal of Suzhou Institute of Education, 1, 106-108.

[6] Yuan Bu. (1992).Three factors influencing the memory of English words. Foreign Language Teaching and Research, 12, 96-100.

[7] Yu Minghong. (2001). Fast memory of English words with the help of roots and affixes. Beijing: World Affairs Press.

Qu Tang was born in Sichuan, China in 1968. He received his Master's Degree in linguistics from Zhong Shan University, China in 2009.

$\mathrm{He}$ is currently an associate professor in College of Foreign Studies, Guilin University of Technology Guilin, China. His research interests include translation theories and teaching strategies. 